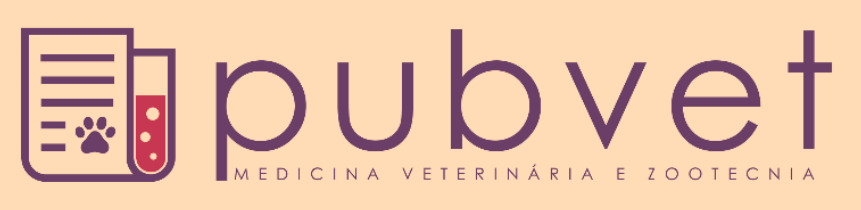

https://doi.org/10.31533/pubvet.v14n8a635.1-4

\title{
Astrovirose canina: Revisão
}

\author{
Alonso Faustino de Souza Filho ${ }^{\bullet}$, Maísa Bernabé ${ }^{1}$, Erick Cabral Coelho ${ }^{1}{ }^{\ominus}$, Rafael Miranda \\ Binda $^{1}{ }^{\ominus}$, Solimar Felipe Contarini de Oliveira $^{1}{ }^{\circ}$, Luiz Alexandre $\operatorname{Moscon}^{2}{ }^{\circ}$, Jessica Miranda \\ $\operatorname{Cota}^{20}$, Clairton Marcolongo Pereira ${ }^{2 *} *$
}

${ }^{1}$ Alunos de graduação do curso de Medicina Veterinária do Centro Universitário do Espírito Santo - UNESC, Colatina, Espírito Santo, Brasil. ${ }^{2}$ Professores de graduação do curso de Medicina Veterinária do Centro Universitário do Espírito Santo - UNESC, Colatina, Espírito Santo, Brasil.

*Autor para correspondência, E-mail: clairton.marcolongo@terra.com.br

Resumo. Os vírus da família Astroviridae são vírus icosaédricos, de RNA fita simples, não envelopados. Esses vírus infectam seres humanos e outros animais, como os cães. O objetivo desse estudo foi reunir informações sobre a astrovirose canina e alertar aos médicos veterinários sobre sua ocorrência. Cães com menos de sete semanas de idade são mais susceptíveis à infecção. Os animais podem apresentar diarreia, dor abdominal e vômito. O diagnóstico é feito pela microscopia eletrônica ou por detecção molecular das partículas virias nas fezes. O tratamento dessa enfermidade é de suporte e na maioria dos animais a doença é auto-limitante. Chama atenção que os sinais clínicos da astrovirose canina são similares aos de outras doenças entéricas em cães, tais como a parvovirose, a cinomose e a infecção por coronavírus, adenovírus e rotavírus canino. Astrovírus canino deve ser incluído no diagnóstico diferencial dessas enfermidades.

Palavras chave: astrovírus, diarreia, gastroenterite

\section{Canine astrovirus: Rewiew}

Abstract. Viruses in the Astroviridae family are icosahedral, single-stranded RNA, nonenveloped viruses. These viruses infect humans and other animals, such as dogs. The aim of this study was to gather information about canine astrovirus and to alert veterinarians about its occurrence. Dogs under seven weeks of age are more susceptible to infection. Animals may have diarrhea, abdominal pain and vomiting. The diagnosis is made by electron microscopy or by molecular detection of viral particles in feces. The treatment of this disease is supportive and, in most animals, the disease is self-limiting. It is noteworthy that the clinical signs of canine astrovirus are similar to those of other enteric diseases in dogs, such as parvovirus, distemper and canine coronavirus, adenovirus and rotavirus infection. Canine astrovirus should be included in the differential diagnosis of these diseases.

Keywords: astrovirus, diarrhea, gastroenteritis

\section{Astrovirus en perros: Revisión}

Resumen. Los virus de la familia Astroviridae son virus icosaédricos, ARN monocatenario y sin envoltura. Estos virus infectan a humanos y otros animales, como perros. El objetivo de este estudio fue recopilar información sobre el astrovirus canino y alertar a los veterinarios sobre su aparición. Los perros menores de siete semanas de edad son más susceptibles a la infección. Los animales pueden experimentar diarrea, dolor abdominal y vómitos. El diagnóstico se realiza por microscopía electrónica o por detección molecular de partículas virales en las heces. El tratamiento de esta enfermedad es de apoyo y en la mayoría de los animales la enfermedad es autolimitada. Es de destacar que los signos 
clínicos del astrovirus canino son similares a los de otras enfermedades entéricas en perros, como parvovirus, moquillo y coronavirus canino, adenovirus e infección por rotavirus. El astrovirus canino debe incluirse en el diagnóstico diferencial de estas enfermedades.

Palabras clave: astrovirosis, diarrea, gastroenteritis

\section{Introdução}

As gastroenterites infecciosas são uma das causas mais importantes de hospitalização de cães. Determinar os agentes responsáveis pela diarreia nesses animais pode ser um desafio, devido a diversidade de etiologias que podem estar envolvidas nessa enfermidade (Marsilio \& Steiner, 2015). Os vírus representam de $40 \%$ a $60 \%$ dos diagnósticos de gastroenterite nessa espécie em diversos estudos (Alves et al., 2018; Decaro et al., 2011; Mendes et al., 2011). Os principais vírus responsáveis pela gastroenterite canina são: parvovírus canino, coronavírus canino, rotavírus canino, o vírus da cinomose e mais recentemente os astrovírus canino (Bhatta et al., 2019). O objetivo do presente estudo é reunir informações sobre a astrovirose canina e alertar aos médicos veterinários sobre sua ocorrência.

\section{Astrovirose canina}

Os astrovírus foram identificados pela primeira vez em fezes de crianças por meio de microscopia eletrônica em 1975 na Escócia. Anos mais tarde, astrovírus que apresentavam características semelhantes aos dos humanos foram relatados em mamíferos e aves (Martella et al., 2011).

Os astrovírus pertencem a família Astroviridae e possuem um formato icosaédrico semelhante ao de uma estrela. São vírus não-envelopados e seu genoma é composto por um RNA linear simples (Martella et al., 2011). São resistentes a vários tipos de detergentes, valores baixos de $\mathrm{pH}$ e podem resistir ao calor de até $60^{\circ} \mathrm{C}$ por cinco minutos (Quinn et al., 2005). Esses vírus possuem distribuição mundial, com relatos em diversos países, incluindo o Brasil (Alves et al., 2018).

A prevalência dos astrovírus nos animais é bastante variável. Em um estudo realizado na China, foi observado que 12,0\% (22 de 183) dos cães que apresentavam quadros de diarreia testaram positivos no PCR para astro virose (Alves et al., 2018). Em um estudo realizado na França, dos 316 casos de animais com diarreia, 66 (20,9\%) testaram positivo para o vírus (Martella et al., 2011). Na Itália, evidenciou-se que $24,5 \%$ de um grupo de 110 cães que apresentavam sinais clínicos de gastroenterite obtiveram resultados positivos para o vírus e ainda 9,3\% desses cães eram portadores assintomáticos (Martella et al., 2011). No Brasil, em um trabalho de detecção e caracterização genética dos astrovírus, os autores observaram que $26 \%$ de animais com ou sem diarreia testaram positivos (Alves et al., 2018).

A família Astroviridae foi dividida em dois gêneros, Avastrovirus e Mammastrovirus, sendo este último responsável pelas infecções em mamíferos (De Benedictis et al., 2011). Esses vírus possuem alta diversidade genotípica que se originou provavelmente durante a transmissão interespécie (Alves et al., 2018). O Mamastrovirus 5 (MAstV5) é a espécie de astrovírus que acomete cães (Alves et al., 2018). O vírus se replica no citoplasma das células hospedeiras e libera vírions por meio de lise celular (Quinn et al., 2007). Entretanto, pouco se sabe sobre o processo de adsorção e entrada do vírus na célula, bem como sobre os receptores virais que propiciam essa entrada (De Benedictis et al., 2011).

As astroviroses em animais estão associadas a manifestações entéricas, podendo os sinais variarem de brandos a graves, como diarreia, vômito, dor abdominal e em casos mais raros pode vir acompanhada de febre e imunodepressão (Toffan et al., 2009). Recentemente, um astrovírus neurotrópico foi descrito como causa de encefalite não supurativa em bovinos na Europa (Bouzalas et al., 2014). A diarreia observada nos animais infectados ocorre por lesões nas junções celulares no intestino e pelo aumento da permeabilidade das células epiteliais (Johnson et al., 2017).

A transmissão ocorre por meio da via fecal-oral e o período de incubação viral é de aproximadamente quatro dias na maioria das espécies domésticas (Quinn et al., 2005). Em cães, os filhotes com idade igual ou inferior a sete semanas são mais susceptíveis ao vírus (Grellet et al., 2012). Tanto cães com gastroenterite quanto cães assintomáticos podem ser portadores do vírus (Bhatta et al., 2019).

O diagnóstico da astrovirose em cães pode ser feito pela microscopia eletrônica de amostras de fezes ou pelo uso das técnicas de biologia molecular, como o RT-PCR (Beuret, 2004; Rohayem et al., 2004). 
Um teste baseado em ELISA visando a identificação de IgGs específicas para o MAstV5 foi descrita em um estudo (Martella et al., 2011).

O tratamento dessa enfermidade baseia-se em terapia de suporte com o uso de fluidoterapia, aplicação de antieméticos, antibióticos e probióticos (Martella et al., 2012). Até o momento, a infecção por astrovírus é considerada auto-limitante na maioria dos casos (Martella et al., 2011, 2012; Toffan et al., 2009). Não existem vacinas para MAstV5 (Alves et al., 2018).

\section{Considerações finais}

Chama a atenção que a astrovirose canina pode ser uma causa importante de diarreia em cães com menos de sete semanas de idade e que essa enfermidade deve ser incluída no diagnóstico diferencial de animais com diarreia.

\section{Agradecimento}

À Fundação de Amparo à Pesquisa e Inovação do Espírito Santo - FAPES e ao Centro Universitário do Espírito Santo - UNESC.

\section{Referências bibliográficas}

Alves, C. D. B. T., Budaszewski, R. F., Torikachvili, M., Streck, A. F., Weber, M. N., Cibulski, S. P., Ravazzolo, A. P., Lunge, V. R., \& Canal, C. W. (2018). Detection and genetic characterization of Mamastrovirus 5 from Brazilian dogs. Brazilian Journal of Microbiology, 49(3), 575-583. DOI: https://doi.org/10.1016/j.bjm.2017.09.008

Beuret, C. (2004). Simultaneous detection of enteric viruses by multiplex real-time RT-PCR. Journal of Virological Methods, 115(1), 1-8. DOI: https://doi.org/10.1016/j.jviromet.2003.09.005

Bhatta, T. R., Chamings, A., Vibin, J., \& Alexandersen, S. (2019). Detection and characterisation of canine astrovirus, canine parvovirus and canine papillomavirus in puppies using next generation sequencing. Scientific Reports, 9(1), 1-10. DOI: https://doi.org/10.1038/s41598-019-41045-Z

Bouzalas, I. G., Wüthrich, D., Walland, J., Drögemüller, C., Zurbriggen, A., Vandevelde, M., Oevermann, A., Bruggmann, R., \& Seuberlich, T. (2014). Neurotropic astrovirus in cattle with nonsuppurative encephalitis in Europe. Journal of Clinical Microbiology, 52(9), 3318-3324. DOI: https://doi.org/10.1128/jcm.01195-14

De Benedictis, P., Schultz-Cherry, S., Burnham, A., \& Cattoli, G. (2011). Astrovirus infections in humans and animals-molecular biology, genetic diversity, and interspecies transmissions. Infection, Genetics and Evolution, 11(7), 1529-1544. DOI: https://doi.org/10.1016/j.meegid.2011.07.024

Decaro, N., Desario, C., Billi, M., Mari, V., Elia, G., Cavalli, A., Martella, V., \& Buonavoglia, C. (2011). Western European epidemiological survey for parvovirus and coronavirus infections in dogs. The Veterinary Journal, 187(2), 195-199. DOI : https://doi.org/10.1016/j.tvjl.2009.10.027

Grellet, A., De Battisti, C., Feugier, A., Pantile, M., Marciano, S., Grandjean, D., \& Cattoli, G. (2012). Prevalence and risk factors of astrovirus infection in puppies from French breeding kennels. Veterinary Microbiology, 157(1-2), 214-219. DOI: https://doi.org/10.1016/j.vetmic.2011.11.012

Johnson, C., Hargest, V., Cortez, V., Meliopoulos, V. A., \& Schultz-Cherry, S. (2017). Astrovirus pathogenesis. Viruses, 9(1), 22. DOI: https://doi.org/10.3390/v9010022

Marsilio, S., \& Steiner, J. (2015). Feline chronic enteropathies. European Journal Comparative and Practice, 25(3), 78-93.

Martella, V., Moschidou, P., \& Buonavoglia, C. (2011). Astroviruses in dogs. Veterinary Clinics: Small Animal Practice, 41(6), 1087-1095. DOI: https://doi.org/10.1016/j.cvsm.2011.09.001

Martella, V., Moschidou, P., Catella, C., Larocca, V., Pinto, P., Losurdo, M., Corrente, M., Lorusso, E., Banyai, K., \& Decaro, N. (2012). Enteric disease in dogs naturally infected by a novel canine astrovirus. Journal of Clinical Microbiology, 50(3), 1066-1069. DOI: https://doi.org/10.1128/jcm.05018-11

Mendes, R. S., Souza, A. P., Silva, R. M. N., Borges, O. M. M., Torres, L. M., \& Dantas, A. K. F. P. 
(2011). Perfil hematológico e bioquímico de cães com gastroenterite hemorrágica por parvovírus diagnosticados pelo método de imunocromatografia. Acta Veterinaria Brasilica, 5(3), 278-283.

Quinn, P. J., Markey, B. K., Carter, M. E., Donnelly, W. J., \& Leonard, F. C. (2005). Microbiologia veterinária e doenças infecciosas. Artmed.

Rohayem, J., Berger, S., Juretzek, T., Herchenröder, O., Mogel, M., Poppe, M., Henker, J., \& Rethwilm, A. (2004). A simple and rapid single-step multiplex RT-PCR to detect Norovirus, Astrovirus and Adenovirus in clinical stool samples. Journal of Virological Methods, 118(1), 49-59. DOI: https://doi.org/10.1016/j.jviromet.2004.01.016

Toffan, A., Jonassen, C. M., De Battisti, C., Schiavon, E., Kofstad, T., Capua, I., \& Cattoli, G. (2009). Genetic characterization of a new astrovirus detected in dogs suffering from diarrhoea. Veterinary Microbiology, 139(1-2), 147-152. DOI: https://doi.org/10.1016/j.vetmic.2009.04.031

Recebido: 16 de junho, 2020.

Aprovado: 21 de julho, 2020.

Disponível online: 17 de agosto, 2020.

Licenciamento: Este artigo é publicado na modalidade Acesso Aberto sob a licença Creative Commons Atribuição 4.0 (CC-BY 4.0), a qual permite uso irrestrito, distribuição, reprodução em qualquer meio, desde que o autor e a fonte sejam devidamente creditados. 